\title{
LEARNING FROM LOSEABLES
}

\author{
An exercise in critical reflection
}

\author{
Darren J Reed \\ University of York, U.K.
}

Abstract: There are a number of themes and descriptive categorisations of devices in HCI that act as positive common places. These include portable, wearable, and ubiquitous devices. In the this paper the category 'loseables', which includes misplaceables, forgetables and stealables, is offered as an alternative formulation of the self same devices. In a recent keynote address David Benyon proposed that HCI practitioners could utilise their own craft skill and tacit knowledge as users of devices to generate questions about design. He also suggested that there was a place for constructive criticism in relation to design that entails a role similar to that of the literary critic. The critical reflexivity method presented in this paper draws inspiration from these comments, and in combination with Philip Agre's idea of $\mathrm{HCI}$ as a 'critical technical practice', offers an exercise in reflective HCI. It explores the essentially contested meaning inherent in devices and, in so doing, presents not only commentary on design itself - along with the simultaneously constructive and constrictive nature of such terms - but also, and more importantly, generates questions, insights and suggestions for design.

Key words: devices, categorization, $\mathrm{HCI}$.

\section{INTRODUCTION}

This paper started with a witticism: having discovered that my PDA had spent the night in a bush outside my house, I commented to a colleague that 
it wasn't in fact a portable device, $\ldots$ it was a loseable ${ }^{12}$. As I told the story to more people, they replied with their own examples of the ways that they had re-seen the technology around them. As I thought about it, I realised that the act of deliberately redefining the character of the device in this way lead to interesting opinions, questions and insights. What was more, such efforts revealed a prevailing hegemony with $\mathrm{HCI}$ : a set of taken for granted terms that serve as common-places that act to close down discussion about a device's meaning.

\subsection{Learning from loseables}

The question became how this insight could be used productively. For example we might ask how we turn a loseable into a findable - the key ring that beeps when whistled at comes to mind here. It was realised that these alternative categorisations, and their application, open up opportunities for reflection. Critical reflexivity is a first pass at inscribing and advocating a method of renaming, and this paper is a first gathering of what might be some of the method's outcomes and insights. These include a means to work up criticisms of particular categories and designs, the (re-)discovery of the contested nature of a device's meaning and what that might mean for 'design-in-use', and the revelation of examples of experience-throughdialogue with a device.

Underlying the method and its application is the issue of reflexivity.

\section{CONCEPTUAL UNDERPINNING}

\subsection{Reflexivity}

While 'reflexivity appears in many different costumes on many different stages' [2] (p. 6). it is generally understood that reflexivity is 'the capacity of language and of thought - of any system of signification - to turn or bend back upon itself, to become an object to itself, and to refer to itself (p. 2). To Garfinkel, reflexivity is the primordial human capacity [5] and the route through which the lived world is made meaningful. According to the sociologist Alfred Schutz, 'lived experience acquires meaning and is understood only reflexively' [12] (p. 42).

$12^{12}$ I have maintained the (mis) spelling of losable as loseable because of the more obvious combination of loss and ability. The addition of 'able' at the end of words seems to me to be an interesting technique for foregrounding the experience of the active agent or user. 
Ashmore [1] draws out a number of distinguishable definitions of reflexivity, that equate to reflection, constitution and mutual elaboration [11]. 'R-reference' or reflection is the benign gaze of awareness (self- or other-); 'R-constitutive' acknowledges the constructive influences of looking; and ' $\mathrm{R}$-circularity' conveys the back and forth relationship between object and representation that can be seen as a form of dialogue between a thing and its description - a continual and ongoing interaction that Mehan and Woods [8] call the 'hermeneutic spiral' (For a fuller discussion of all these ideas see [11]). Understanding reflexivity as 'reflection', 'constitution' and 'dialogue' is the basis of the critical reflexive method.

\subsection{Critical reflexivity}

What I am calling critical reflexivity then is a first pass at instantiating a method of unsettling meaning that encourages reengagement with a technical object as an artefact (socially or culturally constructed). Such deliberate effort can be seen in other disciplines and methodologies that take reflexivity and foreground its existence in everyday life. For example the 'strong programme' in the sociology of scientific knowledge, uncovers the constructed nature of science by applying a policy of 'impartiality' and 'symmetry' to scientific discovery and development [1]. The programme rejects hindsight and applies equal analysis to scientific failures and successes and looks to the same explanations and causes to both sides of the success/failure dichotomy. By asking for example why we have electric instead of gas powered refrigerators (which would not have the annoying hum), the approach reveals how social processes are the core of so-called objective reasoning.

The strong program is an exercise in irony, in that by enforcing equanimity that doesn't naturally exist in the world insight can be gleaned. In the earlier work of the author the ironic reflexive move was used to make comments about the internal discussion and relationships within ethnomethodology [11]. By creating an approach called pragmatic, ethnomethodology that embodied the 'ideal', the author set up a discussion and critique of extreme views within ethnomethodology, and showed how these ran contra to the disciplines foundational and fundamental commitments to the study of social life.

Already HCI has moved from its quantitative roots in cognitive psychology and computer science towards the qualitative insights of sociolology, ethnography and ethnomethodology. In reaction to an interest in studying technology in domestic settings, there is a growing openness to methodologies from such approaches as critical cultural studies, literary studies, and art and design. With these methods comes a move away from 
experimentation, inductive reasoning and incremental development toward single case arguments, deductive reasoning and individual creativity.

A practitioner of such approaches is Don Norman who is well known for providing his own individual reflections on everyday devices [9]. In a similar vein, David Benyon, in a keynote address at ECCE-12 (European Conference on Cognitive Ergonomics), proposed that $\mathrm{HCI}$ could utilise their own craft skills and tacit knowledge as users of devices to generate a critical voice. The idea that $\mathrm{HCI}$ practitioners should employ 'reflection-in-action' was the theme of a recent workshop at CHI2004 (Computer Human Interaction). Based upon the work of Donald Schön, we can see this as a move toward art practice and away from rationalised design. The growing interest in art approaches has been called the 'aesthetic turn' by Wright and McCarthy [14] (p. ix)

One way that the critical voice has already been heard in $\mathrm{HCI}$ is in the work of Philip Agre. In a discussion of the underlying features of AI research he suggested a form of critical self-reflection or 'critical technical practice' 'in which technology development can be not only an end in itself, but also a means to reflect on the assumptions and attitudes that underpin our [HCl's] ideas about technology and humanity" [10].

Garfinkel talks about making trouble as 'aids to a sluggish imagination': 'procedurally it is my preference to start with familiar scenes and ask what can be done to make trouble' [5] (p. 37). By doing this, layers of sense making can be revealed and engaged with. Critical reflexivity makes trouble by suggesting a feasible alternative categorisation of portable devices. This trouble making reveals design issues and insights. In a similar effort, Bell et al talk to the analytic strategy of 'defamiliarization' in the home [3]. Common-place things are revealed as meaningful and meaning is revealed as flexible fluid and contested.

\section{FROM PORTABLES TO LOSEABLES}

I offer an alternative way to think about portable devices.

\subsection{Lose-ables}

There are a number of things in our life that we are always losing: keys are not in the door, the remote control is no longer on the coffee table, and the spectacles are no longer on the bedside cabinet where you left them the night before. We have developed ways of keeping from losing these things, or at least finding them once they are lost. There's the spectacle string, the key ring that beeps at you when you whistle, and when all else fails there's 
backtracking - searching everywhere that you remember being in the last half hour/half day or half year, depending on your last memory of the thing (although this often changes as your options diminish).

Whether this is put down to forgetfulness, or diminishing mental capacities, losing things bugs us. We are brought to a moment of anxiety as we search the same places over and over again. The underlying commitment is that we shouldn't lose them. There are some things we simply never lose; strangely it is normally the very things that are important to us, that we use everyday, that go missing. When this happens we should call these devices what they are, they are loseables and it's their fault that they are lost. As I spoke to colleagues about my crusade of redefinition, I started to collect instances of loseables and developed a set of subcategories.

The categorisation loseables is populated by the sub categories 'misplaceables', 'stealables' and 'tidyables' (amongst others) and I suggest this categorization be used in place of the single term portable (although I could have picked a number of others). To convey these I will draw on my and other's experiences.

\subsection{Misplaceables}

The primordial loseable is the misplaceable. A misplaceable is a thing that it is possible to put in the wrong place, either by deliberate action (e.g., we put it there) or by accident (e.g., it fell there). An example I will draw on a number of times is my brand new PDA. It is smaller than my earlier device and it does so much more. It is more powerful, has more functions, and is definitely more useful; yet I keep losing it. I have left it at work, when I should have brought it home (and visa versa); I have left it on a chair at a workshop (pointed out to me, thank goodness, as I was leaving the room).

In so many ways this is the perfect device. It has a myriad of functions that I actually use. Aesthetically it is pleasing; and importantly it has that wow feature that generates conversation in the hallway of the computer department. It is dear to me; yet I still keep losing it.

It isn't just that it is small, or that the case is black and blends in. The device is such a central part of my working life that I take it everywhere. It is almost that its immersion in my life means I can forget it. Like a wellchewed pen it has moments of perceptual invisibility.

\subsection{Stealables}

Things go missing; when they do we are forced to ask why. Could it be that we haven't misplaced it, but instead someone has taken it? They have been either moved out of the way (tidied - see later) or deliberately removed. 
An example told to me by a colleague was the concern he felt about his IPod device. An IPod plays digital music. It is small (about $6 \mathrm{~cm}$ by 10 and 2 $\mathrm{cm}$ deep) and is considered to be highly stylish having a white front and shiny chrome back. It is unique in having a bright white set of ear-bud headphones. The problem with these headphones is that because they are highly visible, they advertise what is on the end of them. The aesthetic qualities not only make the devise desirable to the consumer, they also make the wearer vulnerable to the crook. Interestingly the colleague who told me the story has since started to wear an alternative set of black headphones because he has lost the white ones. If we were in a psychological mood, we might make a connection between these two facts. The IPod is also a device that sits in a cradle on the desktop. Its appearance in combination with its accessibility makes it attractive to the thief and its size makes slipping it into a pocket very easy. It is the perfect stealable.

As the number of small, stylish and expensive devices proliferate, we have more and more stealables in our possession.

\subsection{Tidyables}

My final subcategory again draws on my experience of my PDA: I once left it at work and someone tidied it away for me: they squeezed it between things on my filing cabinet, obviously concerned that it would become a stealable. Portable devices are not always being carried around; at some point in the day they are at rest. As our homes and places of work fill up with a number of portable devices there is the greater likelihood that they need places, and that these places will not always be consensual. An example provided by a colleague is that of remote controls and power leads which in his experience tend to congregate. We have a number of remote controls and there are three main ways of dealing with them. The first involves placing them near to where they are used, typically on the coffee table. The second place, probably in reaction to the ugliness of a pile of remotes on the coffee table, is to put them next to the device for which they are designed. However instead of individual remotes next to individual devices, they tend to be put next to the larger device, typically the television. Peculiarly in my own household this congregation can also include remote controls for devices in other rooms. The other example was the power lead. Again these are multiplying and we have a choice: either we can leave them with the device or 'store' them together in a draw, say. Unfortunately the problem then becomes sorting out which lead goes with which device, on each and every occasion, and draw stores other lead, differentiating between different types of leads (see later example of 'fryables'). 


\section{TRANSITIONAL MOMENTS IN MEANING}

A colleague in the computer science department told the story of when his portable camera became a loseable camera. He wished to take the camera with him on a weekend away, but couldn't find it. He searched at work, searched at home, and searched his bag four or five times. In these moments, while he knew the camera was a loseable, he didn't know whether it was a misplaceable, a stealable, a tidyable or something else. In fact, he remarked, he would have been happier if he knew it had been stolen because at least he would have known where it was (and what it was). I have my own example of a transitional moment, one that lasted over 24 hours. I once lost my PDA and searched my house for an hour. I then went to work late at night and searched there. The next day I searched the path from my car to my front door and there it was; it had fallen out of my bag the night before and spent the night in a bush. Like my colleague during this time the device moved from being a misplaceable to being a stealable and back again a number of times. So a loseable has a undefined nature up to the point where it is found its meaning is up for grabs. This indeterminacy caused a good deal of anxiety.

\subsection{Deliberate transitions: turning a loseable into an attachable}

As I mentioned at the beginning of this paper, we are active in dealing with loseables. Another colleague tells the story of how he turned his loseable PDA into an 'attachable' by purchasing a pouch, which hooks onto his belt. His PDA is now carried around with him wherever he goes. He has deliberately redefined his loseable device. What this speaks to is deliberate transitions of meaning, or what McCarthy and Wright call 'appropriation'. Another way to say this is that it is an example of 'design-in-use', which includes other activities such as augmentation and personalisation, and which speaks to the active part users of technology play in defining devices in different ways.

All of these thoughts and insights put me in mind of how useful it was when I redefined things as loseables. Calling my PDA portable simply didn't do it justice and certainly did not capture my daily experience of it. By playing with its meaning by deliberately introducing a transition of meaning I was able to see the device anew and almost instantly make suggestions about how it might be changed. 


\section{DISCUSSION - OUT-COMES AND IN-SIGHTS}

Critical reflexivity then is an analytic version of these everyday activities of transition. However by targeting our appropriation and ascriptions we can unsettle taken for granted acceptance of the 'designed in' features of a device, reflect on its meaning and generate new design ideas.

However the deliberate act of re-defining a device also points to the reflexive nature of all naming, and the action of creating alternative meaning is an example of a dialogue with the device, a dialogue that mediates our experience of it as a particular thing (or alternatively shows how our experience of a thing works to define it and categorise it).

\subsection{Design insight (R-reflection)}

There are a number of design insights to be gleaned from our exercise in critical reflexivity. Firstly, of course, that a device can be defined as a loseable speaks negatively to its design. By deliberately redefining a portable as a loseable we become inclined to ask how we stop it from being a loseable. The earlier example of turning a loseable into an attachable is one practical example of adaptation or augmentation. But the question becomes do we want attachable devices? This after all would be a wearable. Do we want to wear all our devices? The wrist-watch is a case in point; and we could suggest that this has lead to (or is the result of) an increased emphasis on time and efficiency in society. Do we want to become so accountable to our personal digital assistants for example as we are becoming accountable to the mobile telephone? Do we want TV screens in our spectacles, ID card in our forearms, and the like? Design, then, at this level is about making decision about what we want technology to mean for us in the future.

\subsection{Categorisation and meaning as contested ( $R$ - constitutive)}

Meaning is socially constructed: in the laboratory, in the home, in the street, but perhaps more interestingly in research insights such as HCI. That it is possible to find an alternative categorisation speaks to the constructed nature of the meaning of a device and sensitizes us to the idea that a single device has multiple possible meanings. By contrasting portables with loseables we re-introduced the contested nature of the meaning of (in this case) technological devices. A practical example where multiple meanings are prevalent is the home, and we are becoming more sensitive to instances of when technology has different meanings for different family members. A 
nice example was given to me by a colleague who plays digital music through his computer at home. When he doesn't use headphones, he prefers to attach a set of portable speakers so that he can move to a private space and not annoy others with his music.

One interesting insight is that there are everyday moments of meaning transition, in which how a device is perceived is in flux and open to meaning ascription. In the case above it is seen in the moments between recognising a device as falling into the broad category of loseable, and when it is specified as a misplaceable or stealable. These are natural moments of flux of constitutive reflexivity. They speak to times of uncertainty and anxiety.

In terms of our perception of technical devices, Wright and Monk have said that certain devices only become visible when they go wrong, when they no longer perform the function for which they were designed. In our case we might say that the PDA only became visible when it was a problem - when it was missing. It is interesting to compare this idea to that espoused by Weiser and the ubiquitous computer,

"For thirty years most interface design, and most computer design, has been headed down the path of the "dramatic" machine. Its highest ideal is to make a computer so exciting, so wonderful, so interesting, that we never want to be without it. A less-travelled path I call the "invisible"; its highest ideal is to make a computer so imbedded, so fitting, so natural, that we use it without even thinking about it" [13].

Bolter and Gromala [4] say that such notions are impossible. Even if the computer was 'embedded' in space and invisible in the environment, it would still have social and cultural meaning and could never become 'transparent'. It is perhaps then cultural meaning that maintains the visibility of a device; no matter how small it will always have meaning.

More than this, devices have multiple cultural and personal meaning at the same time. Blythe's 'pastiche scenarios', - which key off common literary genres and narratives - show how an IPod can have differing and competitive meaning in the same situation at the same time. For example he creates two alternative understandings, one from a narrative built on Bridget Jones' Diary by Helen Fielding, and another on Trainspotting by Irvine Welsh. The IPod at the centre of the account is at once an object of identity and expression (in how it looks and what songs are stored on it) for Bridget, and at the same time a means to generate cash for drugs for Renton.

The idea of transition also speaks to a device having multiple meanings over time. For example, we can think a device's lifecycle and see how its meaning changes over time. An example can seen in the statement, "it's not cutting edge, it's out of date". (Perhaps at times like these we would prefer that our device becomes a loseable!). 
Finally, meaning transition puts me in mind of the fact that certain meaning ascriptions, hold sway, as though in certain situations certain agents have rights over the core meaning repertoires that we can apply. We might call this a form of asymmetric ascription. I have the sense that the discipline of $\mathrm{HCI}$ works with a set of established and largely taken for granted categorisations. These 'common places' act as resources for amongst other things research groupings (including specialised conferences and journals), funding proposals, and decisions about what is 'in' at any give time. How good it would be, then, to deliberately unsettle some of these asymmetric ascriptions. We might then ask questions like the one inferred above about ubiquitous computers. Do we want computers everywhere, and invisible? As $\mathrm{HCI}$ practitioners it is appropriate that every so often we question our categorisations and their influence.

\subsection{Dialogue and experience (R-circular)}

As we saw earlier, Schutz felt that human experience is only possible because of reflexivity. Garfinkel says that reflexivity is essential and uninteresting, by which he means that it is so ubiquitous and there is no escape (p.8). We are continually in a relationship of reflexivity with the world. Ethnomethodology understands reflexivity as best expressed though the 'documentary method'. Garfinkel describes this notion from Mannheim in the following terms,

'...the method consists of treating an actual appearance as 'the document of,' as 'pointing to,' as 'standing on behalf of a presupposed pattern.... Not only is the underlying pattern derived from its individual documentary evidences, but the individual documentary evidences, in their turn, are interpreted on the basis of 'what is known' about the underlying pattern' [5] (p. 78).

This circular relationship between object and representation is ongoing and continual, and can be seen as a dialogue [8]. Critical reflexivity is a way to engage in a conversation with a device, by introducing a new interpretation of the device as document. And is therefore a method of generating and revealing dialogues with devices.

An interesting feature of these types of dialogue is that they are not one way. That is it is not simply about human interpretation of ambiguous things; the device as document completes the referential circle of meaning. Seen in notions such as Norman's affordances, and when Grint and Woolgar [6] talk about how technology 'configures the user', this circular relationship is key to our experience of a device. At times there are disjunctures in this 
documentary relationship when we find it difficult to reconcile the prescribed categorisation (and prescribed experience) and our own experience. The IPod is typically described as a portable device; yet its battery life requires that its portability be regularly punctuated by being tethered to a charger. Prescribed categorisation and experience are in this instance at odds. In these moments we might shout 'it's not a portable at all!'

\section{SUMMING UP}

There are two underlying features of the above discussion: the first is a tendency towards complexity, the second a tendency towards values. As HCI moves out of the darkness of the laboratory into the light of the social world, it is necessary to deal with reflexive processes of meaning making and the emotional and experiential capital invested in technological devices. Indeed it might seem a tall order in these circumstances to substantiate a discipline that can talk about good design. But it is only by engaging in conversation with devices and the complex meanings and values attached to them, that we can hope to reveal the important issues involved, and provide for future design.

\subsection{Critical reflexivity and irony}

Let us be clear: the suggestion of the alternative category 'loseables' an exercise in irony. It could be that it is useful and can be applied in different situations to improve design. That is fine. However, what I am after is a method of deliberate undermining; a means to unsettle taken for granted notions and open the way to understand our devices anew. The typography is an outcome of this effort and is not meant to stand-alone. The resulting discussion and the insight gleaned from it are the point, not the particular category itself.

Just to underline this I offer the following category of 'fryables'. During my conversations with colleagues about loseables, two instances came to light. The first involved the loseable camera mentioned above, for which there is a socket to plug in a wire to transmit the pictures to a television. The socket is shaped such that it also accepts the power lead of another device. In his relief to find the camera, my colleague inadvertently plugged in the power lead, and watched bemused as smoke emanated from its insides. $\mathrm{He}$ suggested the term fryable as a viable alternative description of his (now charred) camera. Another example presented itself in real time during a telephone conversation with another colleague. As we spoke the colleague started to play absent-mindedly with a paper clip, and then, obviously in 
reaction to the interest he felt in the conversation, he idly inserted the paper clip into the firewire port on his laptop. The expletive he uttered conveyed a transitional moment of meaning as the device fizzed and went blank.

\section{REFERENCES}

[1] Ashmore, M. (1989). The Reflexive Thesis. Chicago: Chicago University Press.

[2] Babcock, B.A. (1980). Reflexivity: Definitions and Discriminations. Semiotica, 30(1/2), $1-14$.

[3] Bell, G., Blythe, M., \& Sengers, P. (In Press) Making by making strange: defamiliarization and the design of domestic technologies.

[4] Bolter, J. D \& Gromala, D. (2003) Windows and Mirrors. Interaction, Design and Digital Art, and the Myth of Transparency, London: MIT Press

[5] Garfinkel, H. (1967). Studies in Ethnomethodology. Cambridge: Polity Press.

[6] Grint, K., \& Woolgar, S. (1997). Configuring the User: Inventing New Technologies. In K. Grint \& S. Woolgar (Eds.), The Machine at Work. Technology Work and Organization. Cambridge: Polity Press.

[7] McCarthy, J., \& Wright, P. (2004). Technology as Experience. London: MIT Press.

[8] Mehan, H., \& Wood, H. (1975). The Reality of Ethonomethodology. New York and London: Wiley-Interscience Publication.

[9] Norman, D. (2004). Emotional Design. New York: Basic Books.

[10] Redmile, D. Designing for Reflective Practitioners: Sharing and Assessing Progress by Diverse Communities. CHI2004 Workshop

http://sigchi.org/chi2004/program/prog_workshops.html\#ws6

[11] Reed, D.J. (2002) Observing and Quoting Newsgroup Messages: Method and Phenomenon in the Hermeneutic Spiral. Doctoral Thesis. Loughborough University.

[12] Schutz, A. (1972). The Phenomenology of the Social World. London: Heinemann Educational Books.

[13] Weiser, Mark. Web page http://www.ubiq.com/hypertext/weiser/UbiHome.html

[14] Wright, P., \& Monk, A. (1991). A cost-effective evaluation method for use by designers. International Journal of Man-machine Studies, 35, 891-912. 